\title{
To Discuss the Different Music Materials for Learners and Analyze the Difference Between Individual and Group Teaching
}

\author{
Mingyue Zhou ${ }^{1}$ \\ ${ }^{1}$ University of Adelaide, Adelaide, South Australia, Australia \\ Correspondence: Mingyue Zhou, University of Adelaide, Adelaide, South Australia, Australia.
}

Received: December 30, 2019

Accepted: January 13, 2020

Online Published: January 15, 2020

doi: 10.20849 /jed.v4i1.701

URL: https://doi.org/10.20849/jed.v4i1.701

\begin{abstract}
Beginning tutor books are preparing for students who exposed to music for the first time. It is the simplest and most basic music teaching materials. Piano beginners can divide into different age groups, such as young beginners, teenagers, and adults. The young beginners about six to ten years old, the teenagers are usually senior students, about thirteen to eighteen, and an adult is a person over the age of eighteen. People of all age groups can become piano beginners, and beginners at different age groups should use different kinds of music textbooks. In this essay, the musical materials for the piano beginner at different age groups are presenting below.
\end{abstract}

Keywords: music material, beginner, teenager, student, teacher, individual, group, musicianship material, sight-reading skill, elementary pupil

\section{Age-Relatedness in Music Beginning Materials}

'Alfred's Basic Piano Lesson Book-Level 1A' is a musical material that is suitable for children about six to ten years old. At first, there are many colorful pictures in the book, and it can attract students' attention and make children are more interested in the teaching content. However, for teenagers or adults, textbooks with too much puerile content will be naive and simplistic (Palmer, et al). In general, it is easier for kids to understand the content of the lesson by using pictures instead of words. For example, a piece is called Skating. However, some kids cannot understand the word, so that it will become more vivid and specific to use cartoon picture to describe it. Moreover, teachers can explain to the students what kind of speed and power should play for better present the theme of the piece through pictures (Palmer, et al).

Also, there are many duet parts in the book, which require the cooperation of teachers and children. Because most of the beginning music materials used by children are focus on playing single notes, it is easy for a child to feel bored and then lose patience (Palmer, et al). Therefore, if the teacher's accompaniment is add in the process of playing, the piece will be more prosperous and diverse, which may stimulate students' curiosity and interest in music (Palmer, et al). Besides, the pieces in most beginning music textbooks used by children are usually the shortest and most straightforward, because children have a shorter attention span than teenagers or adults, and can feel tired when they play works that are too long (Palmer, et al). Most children like short and pleasant songs with strong melody, in this situation, add the words under the stave so that the children can play and sing at the same time, which may increase their passion in learning music and make the piece more fun (Palmer, et al).

Besides, for the new notes learned in the textbook, the piano key and stave are presented together in the form of images for comparison, which can help the child find the correct position on the piano key (Palmer, et al). In practice, images can help children remember what the teacher said in class. For the critical point in the class, bold and large fonts using in the textbook can make children more impressive, and children can also remind to review the highlight in practice after class (Palmer, et al). Thus, teachers select piano teaching materials with funny pictures, colorful words, straightforward content and comprehensive knowledge can help students to cultivate their interest in learning music, and provide teachers with more different teaching direction (Palmer, et al).

'Piano For Teens' is an essential guide with step by step instruction for teenagers, the piano beginners of twelve to seventeen years old (Linn, 2018). Firstly, the design of the cover is mainly base on real person pictures, which may help adolescents find books suitable for their age group more quickly (Linn, 2018). Secondly, the textbook attaches the audio files that help students familiarize with the work before lesson and more professional practice 
the work after class (Linn, 2018). More specifically, teenagers can preview and review knowledge. They can learn about the works by audio before class, which may develop students' initiative of learning (Linn, 2018). After class, audio files may play a demonstration role when students practice individually (Linn, 2018). At the same time, teachers can also use audio as a reference for better teaching (Linn, 2018).

Thirdly, this music textbook explains the styles of works and profiles of many musicians (Linn, 2018). Teenagers usually have stronger learning abilities, and they can accept more information in the lesson than children (Linn, 2018). Besides playing the piece, it is also essential to know the background, style of the piece and the introduction of a composer, which may make students have a deep understanding of the works (Linn, 2018). Fourthly, this music textbook introduces the elementary knowledge of piano in detail by using the form of pictures (Linn, 2018). To be specific, it describes the structure and the name of a component of upright and grand pianos, such as music rack, damper pedal, keyboard cover, lid, upper panel, lower panel, and so on. It also compares the two kinds of pianos, so that adolescents may remember the parts of the piano more intuitively. Moreover, this musical material is also suitable for teachers because it is a reminder of what should teach in the first class for piano beginners (Linn, 2018).

Undoubtedly, how to sit at the piano and proper hand position are two crucial questions that are easily ignored and forgotten by students (Linn, 2018). The sitting posture and hand position of playing the piano have a direct impact on the presentation of the piece, so teachers can do the correct demonstration for the students according to the tips in this textbook. For instance, sit tall on the front half of the bench, elbows should be higher than the keyboard level, keep shoulders relaxed, wrist and back of the hand form a straight line and curve fingers so that fingertips are touching the keys (Linn, 2018). Therefore, this book for teenager piano beginners is a comprehensive teaching material because it contains audio files, basic piano knowledge, and a lucid teaching model, which may enable students and teachers to have a more relaxed and systematic piano learning process (Linn, 2018).

'Adult Piano Adventures' is a textbook exclusive to adult piano beginners or people who want to return to the piano (Nancy \& Faber, 2016). For adult piano beginners, they usually have relatively higher understanding and learning abilities than children and adolescents. So that this music textbook is not only more abundant in content, but also adds some music-theoretical knowledge as a supplement, which may make teachers' teaching logically and students are learning diversely (Nancy \& Faber, 2016).

In particular, the book teaches students to recognize the notes and marks step by step, such as from rhythm to notes value, intervals, chords, tempo, melody, harmony, and the like (Nancy \& Faber, 2016). Adults are more receptive than adolescents and children, combining music theory knowledge with playing practice may help students learn music faster and comprehensive (Nancy \& Faber, 2016). What is more, this book includes the part of class reviews, which means that the teacher can review the content of the last lesson with the students before each class. It may help teachers' teaching more coherent and thorough. Students can deepen their impression of the knowledge by reviewing parts as well.

Moreover, the music material includes over two hours of instructional videos and audio tracks, and it is useful for both students and teachers (Nancy \& Faber, 2016). In detail, it provides a more convenient learning mode for adult beginners who want to learn the piano but have no time for face-to-face tutoring. Teachers can also improve their teaching approach by watching a video and listening to audio to remedy the deficiency in teaching, and absorb more diversified teaching methods (Nancy \& Faber, 2016). Furthermore, the works in the textbook are traditional and widely known, such as 'Rise' 'Shine' 'Nobody Know the trouble I have Seen' 'Greensleeves' and so on. These kind of songs can not only make students feel familiar and more devote to studying, but also may enhance their self- confidence and ability of learn ing actively (Nancy \& Faber, 2016). Thus, 'Adult Piano Adventure' is useful for adult piano beginners. It has dozens of familiar songs, video, audio teaching files, effective methods to reading notes, chords, and other technical marks, which means that the book is a comprehensive and systematic music teaching material.

In conclusion, 'Alfred's Basic Piano Lesson Book $\bullet$ Level 1A' is one of the most suitable teaching materials for piano beginners aged from three to six years old. The colorful design, vivid pictures, and pure melody may stimulate children's interest in piano learning and increase their concentration in the lesson, which can meet most kid's needs and preferences. Also, 'Piano For Teens' is a reliable tutor book not only for teenagers but also for teachers. On the one side, the design and layout of the book are more professional and humanization, rich in content, added the structure of piano, background of works, and composer introduction. On the other side, teachers can use audio files as a reference for more academic teaching. It provides teachers with a systematic teaching process, from sitting posture to knowing piano, remember notes and so on. 'Adult Piano Adventures' is 
a comprehensive textbook; it includes video and audio instructional files, which is very convenient for those adults who do not have time to attend the class. Also, the pieces in textbooks are famous and beautiful, which are attractive to students and may increase their confidence in piano learning.

\section{Discuss the Contrasting Dynamics of Individual and Small-Group Lessons}

Individual music lessons and small group music lessons are two models of music teaching. An individual lesson is a form of one-on-one teaching, and small group course usually consists of two to five students. Different teaching models have different requirements for lesson content so that the teaching effect will be different as well. To some extent, there is no doubt that both individual and small group in teaching and learning have advantages and drawbacks, which requires teachers to make teaching plans according to a different situation to maximize the learning effect of students.

Firstly, in an individual lesson, the relationship between the teacher and the student has a direct and vital impact on the outcome of the student's learning music. More specifically, a teacher may need to spend more time chatting with the student rather than music-making. Frequent communication between teachers and students may help students get rid of tension and restraint. Teachers should pay close attention to the psychological changes of the student's learning because most students may feel constrained and nervous when they are in a severe classroom environment (Crozier \& Scaife 2004). So that if the relationship between teacher and student is not so good, a student will quickly give up and refuse to continue to learn a musical instrument for the reason that they do not like the teacher (Crozier \& Scaife 2004). By contrast, in the small group lesson, the teacher-pupil relationship is less paramount, because teachers need to establish a good relationship with the whole group rather than individual, which means that the possibility of conflicts and clashes between teachers and students is significantly reduced (Crozier \& Scaife 2004).

Also, the positive relationship between students and teachers may help students better integrate into music learning and provide pupils with a pleasant atmosphere, which may let the lesson be more enjoyable (Crozier \& Scaife 2004). Pupils will feel more relaxed and comfortable when they learn with their peers (Crozier \& Scaife 2004). Thus, the teacher plays a crucial role in the personal lesson and need to keep an eye on students' emotion and attitudes in the process. However, for a small group lesson, the teacher should maximize the involvement and engagement of all students and control the overall progress of the classroom (Crozier \& Scaife 2004).

Secondly, small group teaching has some distinct disadvantages. To be specific, each group member has different teaching needs and unique abilities, even different levels of learning music. However, in most group lessons, teachers are more focused on the overall class effect. In the limited time, it is difficult for teachers to find and solve the problems of each student (Harris 2006). So that teachers need to allocate time and content of the lesson reasonably to allow students to show their independence while improving their teamwork skills (Harris 2006).

On the contrary, in an individual lesson, the teacher has enough time to get to know and communicate with the student, such as socioeconomic background, motivation, aptitude, interest, private study, and home cooperation (Harris 2006). This kind of information can help teachers make the teaching plan and direction more suitable for students, and the learning process of students may have significant changes and improvement in a short period (Harris 2006). Therefore, under certain situations, individual courses can make the teaching more targeted and workable than small group lessons, and the personal abilities of students can fully reflect.

However, small group teaching also has benefits that cannot ignore. In detail, small group teaching makes the teaching methods more flexible and makes the lesson more fun (Feldman \& Contzius 2011). Teachers can plan a series of exciting activities to present the content, of course, which may develop students' listening, singing, playing, responding and creating in musical studying (Feldman \& Contzius 2011). For example, the 'Kodaly' teaching method explains that singing games and movement exercises are useful for students' musical development, children should actively participate in music activities, which may help them to understand the connection between art music and folk music (Feldman \& Contzius 2011).

'Kodaly' teaching approach claims that music should combine many forms and instruments. People could use some basic instruments to perform music, such as African drum, cymbals, triangle, tambourine and sometimes the xylophone. Besides, some simple gestures, such as clapping hands and stamping feet, are also used in 'Kodaly' teaching way. It requires music to be practiced and created in a group for improving the variety and artistry of music.

Also, acappella singing is one of a common element of music learning (Feldman \& Contzius 2011). The individual lesson loses the superiority of numbers because it uses the most traditional teaching way, which can make students and teachers feel less stimulated (Feldman \& Contzius 2011). It is very dangerous for students to 
lose interest in the lesson, because the lack of interaction will make the class unattractive, and students will tend to give up study music (Feldman \& Contzius 2011). As a result, one-on-one teaching is more appropriate for some special stages and requirements of students. However, group learning is a fundamental part of the whole music learning experience.

Thirdly, whether in a personal lesson or small group course, teachers should always consider the objective of class, because the objective is the critical point of teaching. For individual teaching, the teacher should make learning goals corresponding to the actual situation of students. Such as lesson goals, short-term goals and longterm goals, which may cultivate students' sense of responsibility and mission, because once the goal is achieving, students will increase their confidence and study persistently with enthusiasm in order to reach the next goal (Colwell \& Hewitt 1992). For the small group lesson, teachers need to set overall goals according to the concentration levels within the group, while not ignoring the independence of each child (Colwell \& Hewitt 1992). Moreover, the objective should be adjusted flexibly by the students' reception in class, and think about how the goal can improve in the next lesson (Colwell \& Hewitt 1992).

In conclusion, in individual teaching, an excellent teacher-pupil relationship has a direct impact on students' learning experience of music. However, in a small group lesson, teachers mainly involve students in a collective atmosphere and enjoy the activities with their peers. What is more, although personal courses allow teachers to have a more comprehensive understanding of students for making a teaching plan, it is easy for students to feel bored and give up to continue learning. Besides, group activities seen as a necessary part of learning music. However, it is difficult for teachers to pay attention to each students' learning situation in limited class time. Finally, the objective is the critical consideration, which should be kept in mind as a teacher, because it helps teachers reflect their teaching results and make better teaching plans.

\section{Discuss General Musicianship Materials for Elementary Level Pupils}

Musicianship includes many aspects in addition to the students' performance skills of the musical instrument, such as sight-reading skills, cognitive skills and aural skills. For music learners in the primary stage, it is necessary to know more comprehensive music knowledge, because sight-reading practice enables students to use the language skillfully. Furthermore, cognitive skills will make students are more familiar with the structure of music and develop students' aural skills aim to know how music will sound without having to play it (Harris 2006). This kind of ability can help students understand music more systematically. In this essay, some functions of general musicianship textbooks are present. For instance, 'AMEB Aural Texts Book', Master your theory Grade two, and 'Improve your sight-reading'. These three musical materials can help students develop their musicianship level from aural, cognitive, and sight-reading aspects.

First of all, 'AMEB Aural Texts Book' is a musical material published by the Australian Music Examinations Board (AMEB 2002). This textbook is designing for listening test students. It contains a large number of recordings, test descriptions, and helpful hints, which may help students to solve the problem of listening to music effectively (AMEB 2002). Undoubtedly, aural ability is critical in music learning because it can change the listeners' perception of music, deeper understand the structure of pieces, and the relationship of melody lines in works (Hallam 1998). In this textbook, all melodies are composing of different dynamics, pitches, and rhythm (AMEB 2002). For instance, through constant practice and training, students have to be able to recognize that the position of pitches, higher or lower, softer or louder. And students need to use their hearing to remember and judge the differences and similarities in rhythm between two musical sentences of the same length (AMEB 2002).

Also, the book offers a wealth of audio recordings, providing a more convenient way for students who do not have musical instruments at home to practice (AMEB 2002). So that students will be able to think and feel what they heard by listening to the audio records repeatedly. In this situation, teachers should encourage them to write down the records, their thoughts, and feeling, which may deepen students' impression of listening contents. Besides, the textbook highlights some unique and complicated pitches, rhythms, tempo, and dynamics, which may not only play the role of reminding in students' training but also help them avoid mistakes as much as possible (AMEB 2002). Thus, 'AMEB Aural Texts book' is a helpful guide to improve students' musical aural skills.

Secondly, 'Master your theory Grade two' is an instruction book that is combining with theoretical knowledge and practical exercise (Holland 1994). Musical theory is an essential part of the process of learning music, which means that it expresses music visually and logically to learners (Hallam 1998). More specifically, this is a comprehensive and planned textbook, students will begin with the purest knowledge, and then gradually increase the content in difficulty and depth (Holland 1994). By reading this textbook, students can not only know how to 
use notations such as treble clef, bass clef, quaver, crochet, and rest but also understand the tempo marks and expressive marks, such as allegro, presto, piano, forte and so on (Holland 1994).

What is more, each lesson in the textbook shows the key-point at first and then designs a series of exercises for students to complete, which means that relating theory to practice, enabling students to absorb and digest class content step by step (Holland 1994). Besides, this textbook contains specific instructions and exercises that allow students to work independently without the guidance of a teacher, which may develop students' independent learning ability while solving the problem that the lesson time is too short. There is not enough time for theoretical training (Holland, 1994). In other words, the lesson one explains the meaning and structure of major scales, tone, and semitone. Then there will be corresponding exercises for students to train and consolidate. For example, write one octave descending of $\mathrm{G}$ major in semibreves, write an octave of D major in the treble, note where the sharps come, mark the semitones, then name the sharps (Holland 1994). Therefore, this musicianship material is useful for students who may improve their understanding of music theory.

Thirdly, ' Improve your sight-reading' is a workbook including the number of practice tests and examination database for enhancing students' ability of sight-reading, which is very professional and all-rounded (Harris 2009). Sight-reading skill is very crucial because students with strong sight-reading ability can not only develop their practice efficiency and performance level but also save class time. Teachers can spend more time on cultivating students' musicality (Harris 2006). This book shows the correct and specific steps of sight-reading. In detail, it is necessary that students really know how rhythm work, and then think about which fingering is suitable. Try to perform the piece in the head firstly before they find the correct hand position, do not begin playing until they are pretty sure they know exactly how the piece goes (Harris 2009).

Moreover, each lesson in the book lists prime questions for students to consider before they start rhythmic and melodic training. For instance, how many beats are there in each bar? Tap the rhythm then hear the rhythm silently in your head, can you spot melodic patterns (Harris 2009)? These questions can effectively help students prepare well before playing. Because many mistakes can avoid when students have careful preparation, once they complete a piece of the sight-reading task, they will become more confident and motivated to continue to finish the next task (Harris 2006). Also, this book teaches students how to clap the exercise and tap the pulse with the foot, and the reason is that it may increase students' coordination skills as well as enable them to read faster (Harris 2009). Thereby, this workbook is available for students to build up their musical vocabulary in order to be a good sight-reader.

To sum up, students and teachers can use 'AMEB Aural Texts book' for promoting students' aural skills because students may be able to listen to the rhythms, pitches, and tempos accurately by reading this textbook. Furthermore, 'Master your theory Grade two' provides students and teachers with a better understanding of detailed musical theory, such as harmony, notations, and structure, which can teach students to play expressively. Finally, 'Improve your sight-reading' is one of the most beneficial musicianship materials for students and teachers, because it directly affects the attitude and development of students' learning music experience.

\section{References}

AMEB. (2002). AMEB Aural Texts Book. Australian Music Examinations Board, Melbourne.

Colwell, R. J., \& Hewitt, M. P. (1992). The Teaching of Instrumental Music. Prentice-Hall, USA.

Crozier, R., \& Scaife, N. (2004). All Together! Teaching music in groups. ABRSM, London.

Feldman, E., \& Contzius, A. (2011). Instrumental Music Education. Routledge, New York.

Hallam, S. (1998). Instrumental Teaching. Heinemann Educational Publishers, Chicago.

Harris, P. (2006). Improve your teaching! An essential handbook for instrumental and singing teachers. Faber Music Ltd, London.

Harris, P. (2009). Improve your sight-reading!. Faber Music Ltd, London.

Holland, D. (1994). Master Your Theory 2. EMI Music Publishing, Adelaide.

Linn, J. (2018). Piano for teens. Hal Leonard, USA.

Nancy, F. R. (2016). Adult Piano Adventures. Hal Leonard, USA.

Palmer, W. A., Manus, M., \& Lethco, A. V. (1993). Alfred's Basic Piano Lesson Book • Level 1A. Alfred's Basic Piano Library, USA.

\section{Copyrights}

Copyright for this article is retained by the author(s), with first publication rights granted to the journal.

This is an open-access article distributed under the terms and conditions of the Creative Commons Attribution license (http://creativecommons.org/licenses/by/4.0/). 